\title{
Role of HSP27 in the multidrug sensitivity and resistance of colon cancer cells
}

\author{
ZHENGYONG LIU ${ }^{1 *}$, YI LIU ${ }^{2 *}$, YUPENG LONG ${ }^{3}$, BAOHUA LIU ${ }^{1}$ and XIANGFENG WANG ${ }^{1}$ \\ Departments of ${ }^{1}$ General Surgery and ${ }^{2}$ Information, Daping Hospital, \\ Army Medical University, Chongqing 400042; ${ }^{3}$ Department of Clinical Laboratory, \\ Army 958 Hospital of The Chinese People's Liberation Army, Chongqing 400020, P.R. China
}

Received February 1, 2019; Accepted November 19, 2019

DOI: $10.3892 / 01.2020 .11255$

\begin{abstract}
Multidrug resistance in cancer cells is a primary factor affecting therapeutic efficacy. Heat shock $27 \mathrm{kD}$ protein 1 (HSP27) is associated with cell apoptosis and resistance to chemotherapy. However, the mechanisms underlying HSP27-associated pathways in colon cancer cells remain unclear. Therefore, the present study used short hairpin (sh) RNA to inhibit HSP27 expression in colon cancer cells in order to investigate the effects in vitro and in vivo. Flow cytometry was used to investigate cell apoptosis and a xenograft model was employed to examine the tumorigenesis. Protein expression was measured by Western blotting. The results revealed that suppression of HSP27 expression significantly increased cell apoptosis, inhibited tumor growth and enhanced sensitivity to the anti-cancer agents 5-fluorouracil (5-FU) and vincristine (VCR). shHSP27 significantly decreased the expression of notch receptor 1 and the phosphorylation level of Akt and mTOR, and enhanced the effect of 5-FU and VCR. In conclusion, HSP27 suppression enhanced the sensitivity of colon cancer cells to 5-FU and VCR, and increased colon cancer cell apoptosis with and without chemotherapy. Therefore, the development of novel therapeutic agents that inhibit the expression of HSP27 may offer a new treatment option for colon cancer.
\end{abstract}

\section{Introduction}

Colon cancer is one of the most prevalent cancers worldwide $(1,2)$. Data from the United States of America revealed that $>1.4$ million people were diagnosed with colorectal cancer before 2016 (1). The morbidity and mortality of colon cancer are gradually increasing

Correspondence to: Dr Baohua Liu or Dr Xiangfeng Wang, Department of General Surgery, Daping Hospital, Army Medical University, 10 Changjiangzhilu Road, Yuzhong, Chongqing 400042, P.R. China

E-mail: LBH57268@163.com

E-mail: xiangfengwang@tmmu.edu.cn

"Contributed equally

Key words: heat shock $27 \mathrm{kD}$ protein 1, notch receptor 1-Akt-mTOR pathway, multidrug sensitivity, colon cancer worldwide $(2,3)$. Although adjuvant chemotherapy has been used to reduce the risk of tumor recurrence and improve survival $(4,5)$, the 5-year survival rates of patients with colon cancer remain unfavorable due to the presence of multidrug resistance in colon cancer cells (6). Chemoresistance develops in the majority of patients with colon cancer, and leads to a decrease in the therapeutic efficacy and potential failure of anticancer agents $(6,7)$.

A number of cellular and non-cellular mechanisms conferring chemoresistance have been described (8-10). Heat shock proteins (HSPs), which increase the migration and invasion of cancer cells and decrease apoptosis, are involved in both cellular and non-cellular resistance in cancer cells $(11,12)$. Heat shock $27 \mathrm{kD}$ protein 1 (HSP27), a member of the HSP family, has been revealed to influence both oncogenesis and chemotherapeutic resistance (13). Previous studies have shown that the upregulation of HSP27 is associated with cell apoptosis and resistance to chemotherapy and radiotherapy in breast (14), lung (15) and colon cancer $(16,17)$. The downregulation of HSP27 may therefore increase the sensitivity of colon cancer cells to several chemotherapeutic agents, including 5-fluorouracil (5-FU) (18), cisplatin (19) and SN38 (20).

HSP27 was found to decrease apoptosis in cancer cells, an effect that contributes to chemoresistance $(13,17)$. However, the underlying mechanisms in colon cancer cells remain unclear. Furthermore, cross-talk among the notch receptor 1 (NOTCH1), mTOR and PI3K/Akt signaling pathways is associated with apoptosis (21). The binding of NOTCH1 to its ligands allows DNA-binding proteins to regulate the expression of NOTCH1 target genes, which are involved in the proliferation, differentiation and apoptosis of various tumor cells (22-24). Additionally, PI3K and its effectors, including Akt and mTOR, play a key role in the proliferation and survival of tumor cells (25). The NOTCH1-Akt/mTOR signaling pathway has been recognized as a potential therapeutic target for the treatment of cancer (26). Therefore, the present study investigated the effect of suppressing HSP27 on multidrug sensitivity in colon cancer cells and explored the NOTCH1-Akt-mTOR signaling pathway as an underlying mechanism.

\section{Materials and methods}

Cell culture and treatment with chemotherapeutic agents. The human colon cancer cell line SW480 (27) was obtained from 

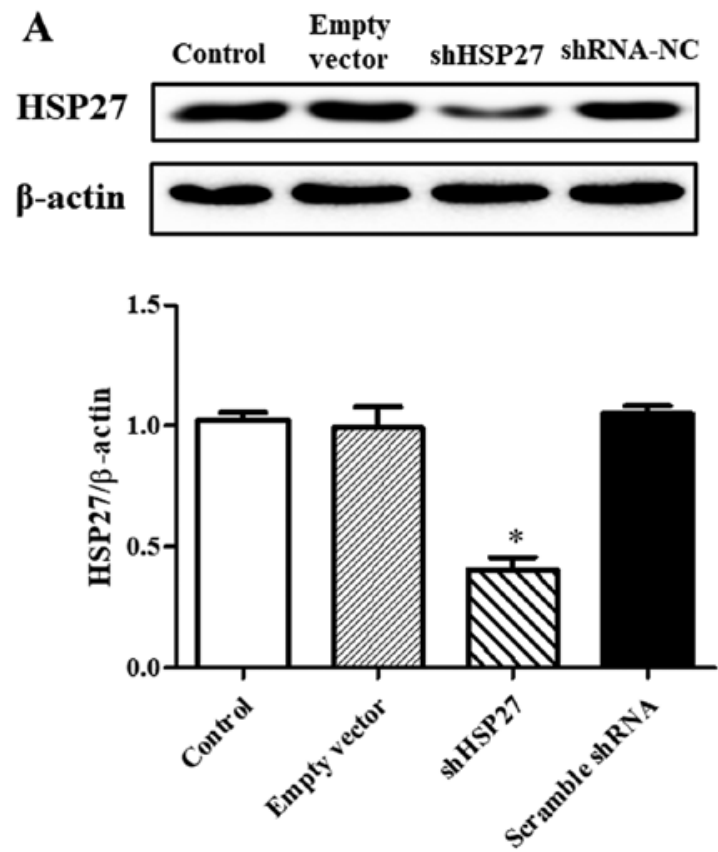
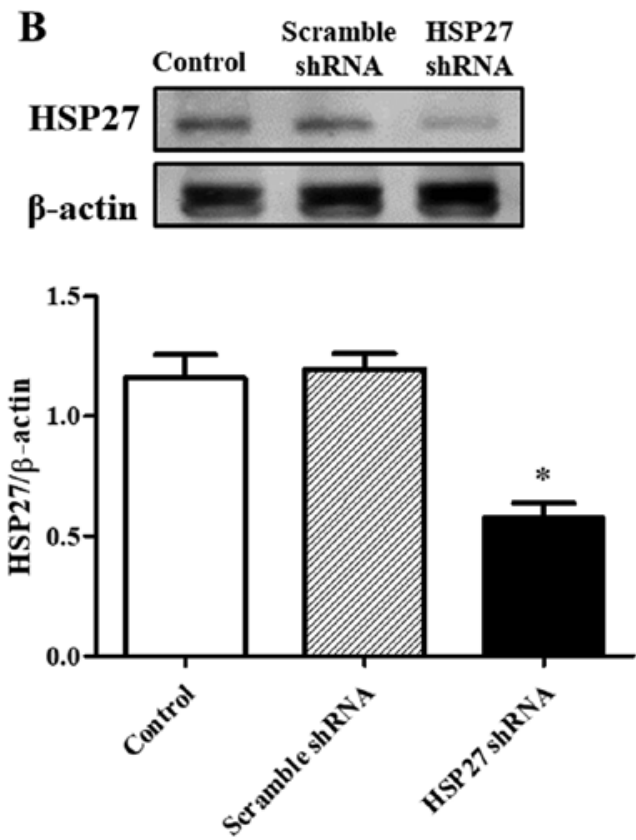

Figure 1. Effect of shHSP27 on HSP27 expression (A) in vitro and (B) in vivo. Results are expressed as the ratio of HSP27 and $\beta$-actin. * $\mathrm{P}<0.05$ vs. the others. $\mathrm{n}=4$ in each group. sh, short hairpin; HSP27, heat shock $27 \mathrm{kD}$ protein 1; NC, negative control.

the American Type Culture Collection (ATCC) and cultured in ATCC-formulated Leiboviz's L-15 medium (Biowest) supplemented with $10 \%$ fetal bovine serum (Gibco; Thermo Fisher Scientific, Inc.) at $37^{\circ} \mathrm{C}$ and $5 \% \mathrm{CO}_{2}$. The chemotherapeutic agents 5-FU and vincristine (VCR; both Sigma-Aldrich; Merck $\mathrm{KGaA}$ ) were diluted with phosphate-buffered saline (PBS). SW480 cells were treated with $50 \mu \mathrm{g} / \mathrm{ml} \mathrm{5-FU} \mathrm{(16)} \mathrm{and}$ $16 \mu \mathrm{M}$ VCR (28) at $37^{\circ} \mathrm{C}$ for $48 \mathrm{~h}$.

Short hairpin (sh) RNA HSP27 transfection in vitro. SW480 cells were transfected with a lentivirus delivering shHSP27 as previously described $(29,30)$. Briefly, SW480 cells $\left(1 \times 10^{6}\right.$ per well) were plated in 12-well plates and incubated overnight at $37^{\circ} \mathrm{C}$. The cells were subsequently transfected with the pLVX-shHSP27 lentivirus or an empty lentiviral vector as control $\left(1 \times 10^{10} \mathrm{pfu} / \mathrm{ml}\right.$; Shanghai Genechem, Co., Ltd.). The sequence of the shRNA targeting HSP27 used in the present study was as follows: 5'-AGCTGACGGTCAAGACC AA-3' (31). Scrambled shRNA (5'-TGACGATAAGAACAA TAAC-3') was used as the negative control. Cells were incubated with the lentiviruses at $37^{\circ} \mathrm{C}$ for $72 \mathrm{~h}$. The transfection efficiency was determined by western blotting.

Flow cytometry. SW480 cells $\left(1 \times 10^{6}\right.$ per well) were collected and suspended in PBS in a $1 \mathrm{ml}$ eppendorf tube. The cells were subsequently stained with $10 \mu \mathrm{l}$ Annexin V-FITC and $5 \mu \mathrm{l}$ propidium iodide (PI; Roche Applied Science) according to the manufacturer's instructions. The percentages of apoptotic SW480 cells transfected with shHSP27 and treated with the chemotherapeutic agents were investigated using a flow cytometer and analyzed with FlowJo software (version 10.0; FlowJo LLC).

Xenograft model in nude mice. A total of 24 male nude mice (weight, 15-20 g) were purchased from Vital River Laboratory
Animal Technology Co., Ltd. and randomly divided into 6 groups as follows: i) Control; ii) shHSP27; iii) control + 5-FU; iv) control + VCR; v) shHSP27 + 5-FU; and vi) shHSP27 + VCR. A total of $1 \times 10^{6}$ SW480 cells transfected with shHSP27 or scrambled shRNA, suspended in $100 \mu$ l PBS, were subcutaneously injected into the left axilla. At 3 days post-injection, the mice were treated with $50 \mathrm{mg} / \mathrm{kg} /$ week $5-\mathrm{FU}, 80 \mathrm{mg} / \mathrm{kg} /$ day VCR or PBS intraperitoneally for 21 days. The mice were subsequently euthanized by the intraperitoneal injection of $200 \mathrm{mg} / \mathrm{kg}$ sodium pentobarbital. The tumor tissues were collected for further study and the tumor volume was calculated using the formula: (length $\mathrm{x}$ width ${ }^{2}$ )/ 2 as previously described (32).

The present study was approved by the Research Council and Animal Care and Use Committee of Daping Hospital, Army Medical University. All experiments conformed to the guidelines of the American Association for the Accreditation of Laboratory Animal Care (33).

Western blotting. SW480 cells or tumor tissues were lysed in lysis buffer (Beyotime Institute of Biotechnology). The protein concentrations were measured using a bicinchoninic acid (BCA) protein assay kit (Hyclone Pierce). Protein homogenates (20 $\mu \mathrm{g} /$ lane) were separated by SDS-PAGE on a $8-10 \%$ gel and transferred onto polyvinylidene fluoride membranes. The membranes were washed with Tris-buffered saline (TBS) and blocked with $5 \%$ milk powder in TBS at room temperature for $1 \mathrm{~h}$. The membranes were incubated with primary antibodies against phospho-Akt (1:1,000; cat. no. 4060; Cell Signaling Technology, Inc.), Akt (1:1,000; cat. no. 4691; Cell Signaling Technology, Inc.), phospho-mTOR (1:1,000; cat. no. 2971; Cell Signaling Technology, Inc.), mTOR (1:1,000; cat. no. 2983; Cell Signaling Technology, Inc.), NOTCH1 (1:1,000; cat. no. 3608; Cell Signaling Technology, Inc.) and $\beta$-actin $(1: 1,000$; cat. no. sc-376421; Santa Cruz Biotechnology, Inc.) at $4^{\circ} \mathrm{C}$ over 


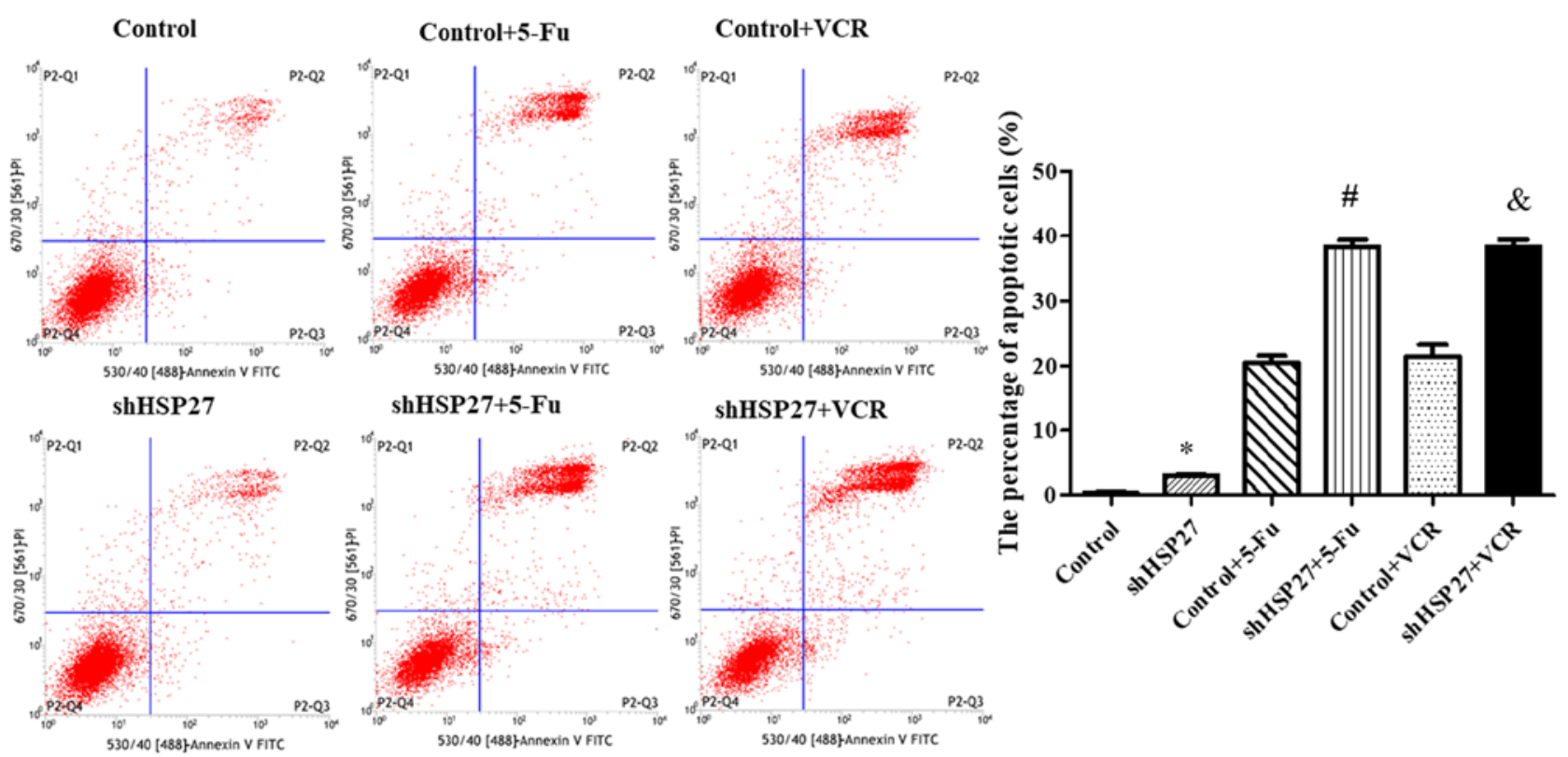

Figure 2. Annexin V-FITC/PI staining of SW480 cells with/without shHSP27 and chemotherapy. ${ }^{\text {"P }}<0.05$ vs. the other groups, ${ }^{~} \mathrm{P}<0.05$ vs. control +5 -FU group, ${ }^{\circledR} \mathrm{P}<0.05$ vs. control + VCR group. $\mathrm{n}=5$ in each group. sh, short hairpin; HSP27, heat shock $27 \mathrm{kD}$ protein 1; 5-FU, 5-fluorouracil; VCR, vincristine.

for $12 \mathrm{~h}$. Then, the primary antibodies were detected with goat anti-rabbit-IgG secondary antibodies (1:5,000; Abcam; cat. no. ab6721) conjugated to horseradish peroxidase, and the bands were visualized with enhanced chemiluminescence (Pierce; Thermo Fisher Scientific, Inc.). The optical density (OD) value was analyzed with Quantity One (Version 4.6.2; Bio-Rad Laboratories, Inc.). $\beta$-actin served as the loading control. Each western blotting was performed $\geq 3$ times.

Statistical analysis. Statistical analyses were performed using SPSS software (version 22.0; IBM Corp.). Comparisons between $\geq 3$ groups were conducted using one-way ANOVA, and comparisons among groups were conducted using one-way ANOVA followed by the Holm-Sidak post hoc test. The data are expressed as the mean $\pm \mathrm{SEM}$. $\mathrm{P}<0.05$ was considered to indicate a statistically significant difference.

\section{Results}

Suppression of HSP27 expression in SW480 cells. In order to inhibit HSP27 expression, SW480 cells were transfected with a lentiviral vector delivering shHSP27. SW480 cells transfected with an empty lentiviral vector or a lentiviral delivering scrambled shRNA served as the controls. As shown in Fig. 1A, the expression of HSP27 in SW480 cells transfected with shHSP27 was significantly decreased compared with the controls. Further in vivo studies revealed that HSP27 expression in tumor tissue was decreased in mice injected with the shHSP27-transfected cells compared with the controls (Fig. 1B).

Role of HSP27 suppression in cancer cell growth and multidrug sensitivity. To further determine the role of HSP27 suppression in cancer cell growth, SW480 cells were transfected with shHSP27 and treated with two chemotherapeutic agents, 5-FU and VCR. Annexin V-FITC/PI staining and flow cytometry revealed that the percentage of apoptotic cells was

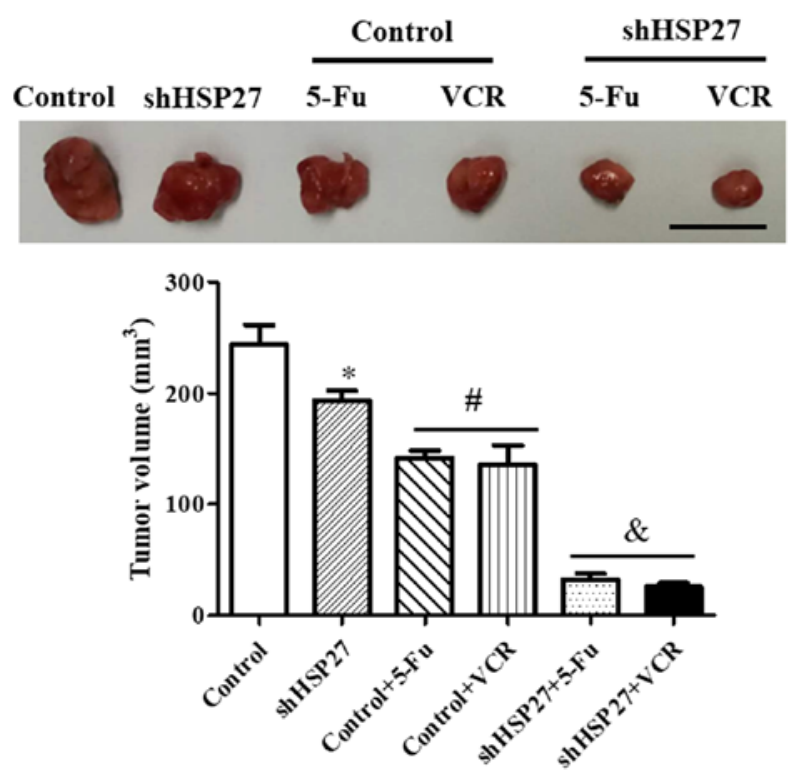

Figure 3. Tumor sizes in the xenograft model. ${ }^{*} \mathrm{P}<0.05$ vs. the other groups, ${ }^{\#} \mathrm{P}<0.05$ vs. control, ${ }^{\&} \mathrm{P}<0.05$ vs. control $+5-\mathrm{FU}$ or control $+\mathrm{VCR}$. $\mathrm{n}=4$ in each group. sh, short hairpin; HSP27, heat shock $27 \mathrm{kD}$ protein 1; 5-FU, 5-fluorouracil; VCR, vincristine. Scale bar=100 mm.

increased in shHSP27-transfected cells compared with the controls (Fig. 2). Although treatment with 5-FU and VCR alone increased the percentage of apoptotic SW480 cells, the combination of shHSP27 and chemotherapeutic agents resulted in a greater increase in the percentage of apoptotic cells compared with the control groups (Fig. 2).

The volumes of the tumors obtained from the nude mice were subsequently calculated. The data revealed that mice injected with shHSP27-transfected SW480 cells exhibited smaller tumors compared with the control group. Furthermore, shHSP27-transfected SW480 cells increased the inhibitory 

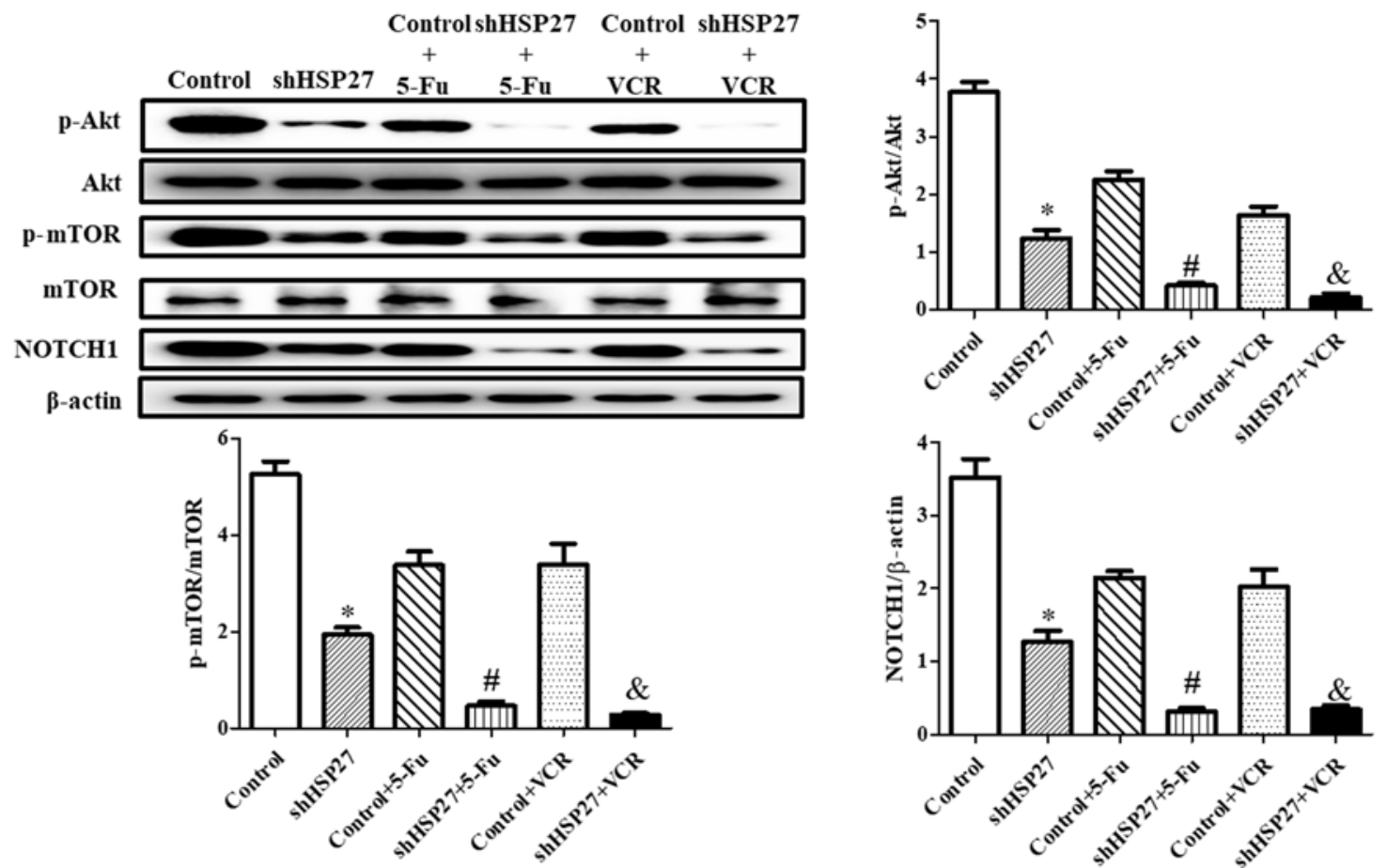

Figure 4. Effect of shHSP27 and chemotherapy on the phosphorylation and expression of the NOTCH1-Akt-mTOR pathway in vitro. ${ }^{*} \mathrm{P}<0.05$ vs. the other groups, ${ }^{\sharp} \mathrm{P}<0.05$ vs. control +5 -FU group, ${ }^{\circledR} \mathrm{P}<0.05$ vs. control + VCR group. $\mathrm{n}=4$ in each group. sh, short hairpin; HSP27, heat shock $27 \mathrm{kD}$ protein $1 ;$ NOTCH1, notch receptor 1; 5-FU, 5-fluorouracil; VCR, vincristine; $\mathrm{p}$, phosphorylated.
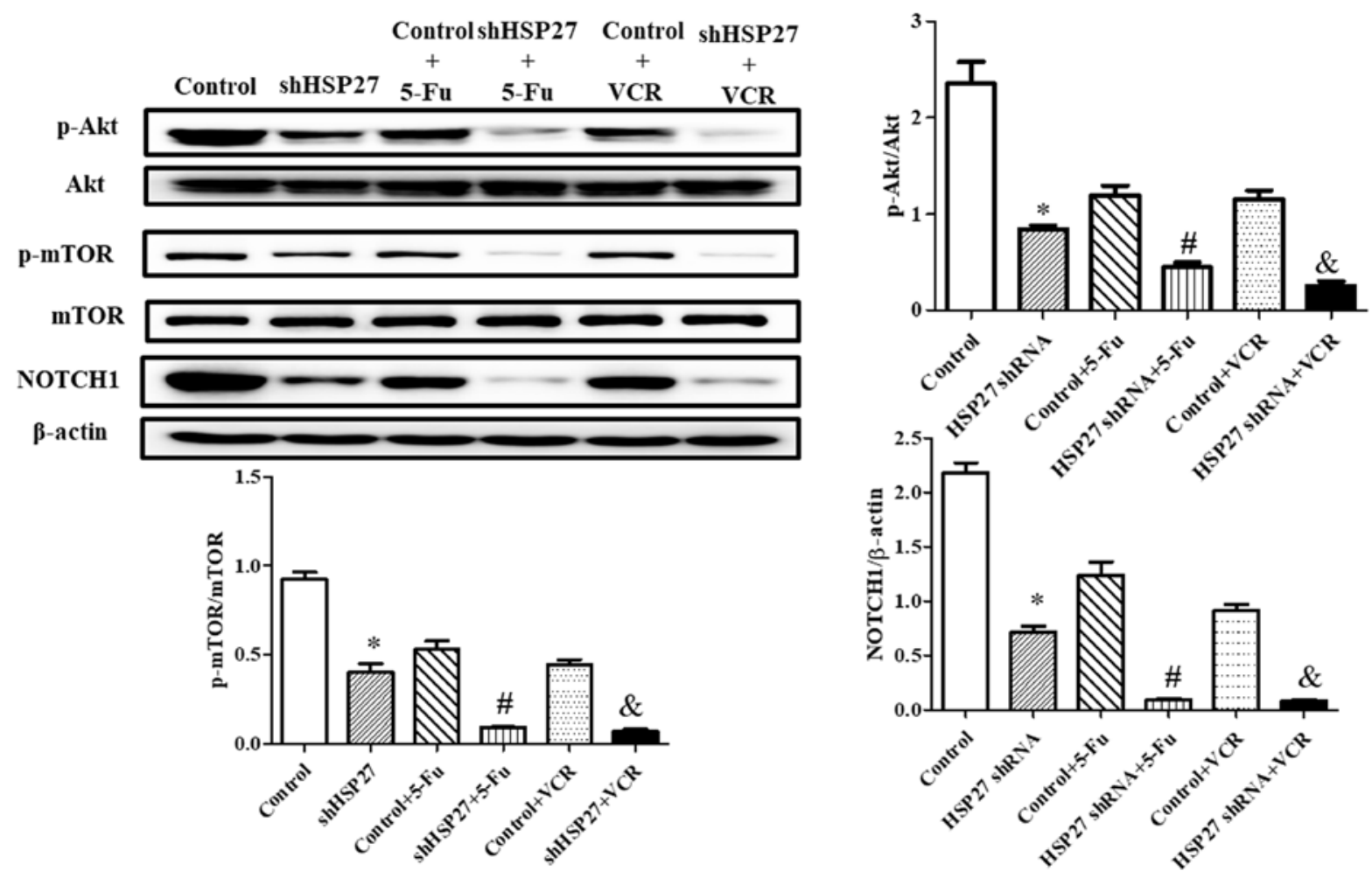

Figure 5. Effect of shHSP27 and chemotherapy on the phosphorylation and expression of the NOTCH1-Akt-mTOR pathway in vivo. "P<0.05 vs. the others, ${ }^{\text {"P }} \mathrm{P}<0.05$ vs. control + 5-FU group, ${ }^{\text {\& }} \mathrm{P}<0.05$ vs. control + VCR group. $\mathrm{n}=4$ in each group. sh, short hairpin; HSP27, heat shock $27 \mathrm{kD}$ protein 1 ; NOTCH1, notch receptor 1; 5-FU, 5-fluorouracil; VCR, vincristine.

effect of 5-FU and VCR on tumor growth (Fig. 3), indicating that the suppression of HSP27 might increase sensitivity to anti-cancer agents.
HSP27 suppression decreases chemoresistance via the NOTCH1-Akt-mTOR signaling pathway. The present study revealed that HSP27 suppression significantly decreased 
NOTCH1 expression and the phosphorylation level of Akt and mTOR. shHSP27 enhanced the effect of 5-FU and VCR on the downstream Akt-mTOR signaling pathway (34). The decrease in the expression of NOTCH1 and the phosphorylation level of Akt and mTOR following 5-FU or VCR treatment was increased in shHSP27-transfected cells in vitro (Fig. 4) and in vivo (Fig. 5), compared with the controls.

\section{Discussion}

Previous studies have attempted to improve the treatment of colon cancer by combining 5-FU with other agents, such as VCR $(2,4,5,35)$. However, due to multidrug resistance, chemotherapy sensitivity is decreased and chemotherapeutic efficacy is limited, and is a major clinical challenge in the treatment of colon cancer (36). As a chaperone protein that stabilizes proteins under stress, HSP27 is associated with chemoresistance in various cancer cells $(19,37,38)$. Cell proliferation and anti-apoptotic mechanisms have been identified as the main causes of chemoresistance and poor patient prognosis (6-8). Therefore, the role of HSP27 in chemoresistance remains unclear.

In the present study, shRNA was used to decrease the expression of HSP27 in SW480 cells. The results revealed that suppression of HSP27 expression significantly increased cell apoptosis and inhibited tumor growth, and enhanced sensitivity to 5-FU and VCR, compared with the controls.

Increasing evidence has revealed the role of HSP27 in 5-FU resistance in colon cancer cells (15-20). Increased expression of HSP27 resulted in greater resistance to 5-FU in colon cancer cells $(18,39)$, whereas suppression of HSP27 via gene knockdown $(16,38)$ or pharmaceuticals $(39,40)$, enhanced sensitivity to 5-FU. Moreover, HSP27 is associated with VCR resistance in cancer cells (41). Proteome analysis indicated that HSP27 is differentially expressed between VCR-sensitive and VCR-resistant human gastric carcinoma cells (41). Furthermore, suppression of HSP27 expression enhanced VCR chemosensitivity and induced the cancer cells to exhibit apoptotic morphological features following VCR treatment (41). The data in the present suggested that decreased expression of HSP27 contributed to decreased VCR resistance.

5-FU and VCR exert their anti-cancer effect by inducing apoptosis, mainly through the Akt-mTOR signaling pathway $(42,43)$. Evidence shows that the Akt/mTOR signaling pathway is a major negative regulator of apoptosis $(43,44)$. Decreased cell apoptosis, which is induced by increased Akt/mTOR activation, also plays a key role in drug resistance (45). HSP27, which acts as a scaffold protein, can directly bind to Akt, resulting in increased phosphorylation of Akt and mTOR. This activates the Akt/mTOR signaling pathway and leads to decreased apoptosis and increased chemoresistance in cancer cells $(13,15)$. The results obtained in the present study suggested that the inhibition of HSP27 expression suppressed Akt and mTOR phosphorylation, and increased apoptosis associated with chemotherapeutic agents.

NOTCH1 is involved in the regulation of the Akt/mTOR signaling pathway $(46,47)$, which is widely acknowledged to promote cancer development $(22-26,42)$. The present study revealed that shHSP27 decreased NOTCH1 expression, indicating that HSP27 might regulate chemoresistance in colon cancer cells via NOTCH1 and that NOTCH1 might regulate of HSP27 in the Akt/mTOR signaling pathway. Future studies are required to investigate the interactions between HSP27 and the NOTCH1-Akt/mTOR signaling pathway.

In summary, the present study revealed that HSP27 suppression enhanced the sensitivity of SW480 cells to 5-FU and VCR, and increased the apoptosis of the cells with and without chemotherapy. Therefore, the development of pharmacological agents that inhibit HSP27 expression may offer a new treatment approach for colon cancer.

\section{Acknowledgements}

Not applicable.

\section{Funding}

The present study was supported by the Chongqing Science and Technology Commission of China (grant no. cstc2017jcyjAX0360).

\section{Availability of data and materials}

The datasets used and/or analyzed during the current study are available from the corresponding author on reasonable request.

\section{Authors' contributions}

ZL, BL and XW conceived and designed the study. ZL, YLi and YLo performed the experiments. ZL, YLo and XW wrote the paper. BL, YLi and XW reviewed and edited the manuscript. All authors read and approved the manuscript and agree to be accountable for all aspects of the research.

\section{Ethics approval and consent to participate}

The present study was approved by the Research Council and Animal Care and Use Committee of Daping Hospital, Army Medical University (Chongqing, China). All experiments conformed to the guidelines of the American Association for the Accreditation of Laboratory Animal Care and the tumor burden did not exceed the recommendations of the University of Pennsylvania Institutional Animal Care and Use Committee guidelines.

\section{Patient consent for publication}

Not applicable.

\section{Competing interests}

The authors declare that they have no competing interests.

\section{References}

1. Miller KD, Siegel RL, Lin CC, Mariotto AB, Kramer JL, Rowland JH, Stein KD, Alteri R and Jemal A: Cancer treatment and survivorship statistics, 2016. CA Cancer J Clin 66: 271-289, 2016.

2. Siegel RL, Miller KD, Fedewa SA, Ahnen DJ, Meester RGS, Barzi A and Jemal A: Colorectal cancer statistics, 2017. CA Cancer J Clin 67: 177-193, 2017. 
3. Wiseman M: The second World Cancer Research Fund/American Institute for Cancer Research expert report. Food, nutrition, physical activity, and the prevention of cancer: A global perspective. Proc Nutr Soc 67: 253-256, 2008

4. Gill S, Loprinzi CL, Sargent DJ, Thomé SD, Alberts SR, Haller DG, Benedetti J, Francini G, Shepherd LE, Francois Seitz J, et al: Pooled analysis of fluorouracil-based adjuvant therapy for stage II and III colon cancer: Who benefits and by how much? J Clin Oncol 22: 1797-1806, 2004.

5. Meyerhardt JA: Adjuvant therapy for stage II and III colon cancer. Clin Adv Hematol Oncol 8: 772-774, 2010.

6. Hu T, Li Z, Gao CY and Cho CH: Mechanisms of drug resistance in colon cancer and its therapeutic strategies. World J Gastroenterol 22: 6876-6889, 2016.

7. Dallas NA, Xia L, Fan F, Gray MJ, Gaur P, van Buren G II, Samuel S, Kim MP, Lim SJ and Ellis LM: Chemoresistant colorectal cancer cells, the cancer stem cell phenotype, and increased sensitivity to insulin-like growth factor-I receptor inhibition. Cancer Res 69: 1951-1957, 2009.

8. Holohan C, Van Schaeybroeck S, Longley DB and Johnston PG: Cancer drug resistance: An evolving paradigm. Nat Rev Cancer 13: 714-726, 2013.

9. Kim EK, Jang M, Song MJ, Kim D, Kim Y and Jang HH: Redox-mediated mechanism of chemoresistance in cancer cells. Antioxidants (Basel) 8: E471, 2019.

10. Sharma A: Chemoresistance in cancer cells: Exosomes as potential regulators of therapeutic tumor heterogeneity. Nanomedicine (Lond) 12: 2137-2148, 2017.

11. Chatterjee $S$ and Burns TF: Targeting heat shock proteins in cancer: A promising therapeutic approach. Int J Mol Sci 18: E1978, 2017.

12. Wu J, Liu T, Rios Z, Mei Q, Lin X and Cao S: Heat shock proteins and cancer. Trends Pharmacol Sci 38: 226-256, 2017.

13. Garrido C, Brunet M, Didelot C, Zermati Y, Schmitt E and Kroemer G: Heat shock proteins 27 and 70: Anti-apoptotic proteins with tumorigenic properties. Cell Cycle 5: 2592-2601, 2006.

14. Oesterreich S, Weng CN, Qiu M, Hilsenbeck SG, Osborne CK and Fuqua SA: The small heat shock protein hsp27 is correlated with growth and drug resistance in human breast cancer cell lines. Cancer Res 53: 4443-4448, 1993.

15. Liu CL, Chen SF, Wu MZ, Jao SW, Lin YS, Yang CY, Lee TY, Wen LW, Lan GL and Nieh S: The molecular and clinical verification of therapeutic resistance via the p38 MAPK-Hsp27 axis in lung cancer. Oncotarget 7: 14279-14290, 2016.

16. Shimada T, Tsuruta M, Hasegawa H, Okabayashi K, Shigeta K, Ishida T, Asada Y, Suzumura H, Koishikawa K, Akimoto S and Kitagawa Y: Heat shock protein 27 knockdown using nucleotide-based therapies enhances sensitivity to 5-FU chemotherapy in SW480 human colon cancer cells. Oncol Rep 39: 1119-1124, 2018

17. Liang HH, Huang CY, Chou CW, Makondi PT, Huang MT, Wei PL and Chang YJ: Heat shock protein 27 influences the anti-cancer effect of curcumin in colon cancer cells through ROS production and autophagy activation. Life Sci 209: 43-51, 2018.

18. Hayashi R, Ishii Y, Ochiai H, Matsunaga A, Endo T, Hasegawa H and Kitagawa Y: Suppression of heat shock protein 27 expression promotes 5-fluorouracil sensitivity in colon cancer cells in a xenograft model. Oncol Rep 28: 1269-1274, 2012.

19. Krawczyk Z, Gogler-Piglowska A, Sojka DR and Scieglinska D: The role of heat shock proteins in cisplatin resistance. Anticancer Agents Med Chem 18: 2093-2109, 2018.

20. Ishida T, Ishii Y, Tsuruta M, Okabayashi K, Akimoto S, Koishikawa K, Hasegawa $\mathrm{H}$ and Kitagawa Y: Cetuximab promotes SN38 sensitivity via suppression of heat shock protein 27 in colorectal cancer cells with wild-type RAS. Oncol Rep 38 : 926-932, 2017.

21. Zeng C, Xing R, Liu J and Xing F: Role of CSL-dependent and independent Notch signaling pathways in cell apoptosis. Apoptosis 21: 1-12, 2016

22. Aithal MG and Rajeswari N: Role of Notch signalling pathway in cancer and its association with DNA methylation. J Genet 92 : 667-675, 2013

23. Yang Z, Qi Y, Lai N, Zhang J, Chen Z, Liu M, Zhang W, Luo R and Kang S: Notch1 signaling in melanoma cells promoted tumor-induced immunosuppression via upregulation of TGF- $\beta 1$. J Exp Clin Cancer Res 37: 1, 2018.

24. Gan RH, Wei H, Xie J, Zheng DP, Luo EL, Huang XY, Xie J, Zhao Y, Ding LC, Su BH, et al: Notch1 regulates tongue cancer cells proliferation, apoptosis and invasion. Cell Cycle 17: 216-224, 2018
25. Sambandam V, Frederick MJ, Shen L, Tong P, Rao X, Peng S, Singh R, Mazumdar T, Huang C, Li Q, et al: PDK1 Mediates NOTCH1-mutated head and neck squamous carcinoma vulnerability to therapeutic PI3K/mTOR inhibition. Clin Cancer Res 25: 3329-3340, 2019.

26. Wang Y, Li M, Dong C, Ma Y, Xiao L, Zuo S, Gong Y, Ren T and Sun B: Linc00152 knockdown inactivates the Akt/mTOR and Notch1 pathways to exert its anti-hemangioma effect.Life Sci 223: 22-28, 2019.

27. Witty JP, McDonnell S, Newell KJ, Cannon P, Navre M, Tressler RJ and Matrisian LM: Modulation of matrilysin levels in colon carcinoma cell lines affects tumorigenicity in vivo. Cancer Res 54: 4805-4812, 1994.

28. Cheng C, Xie Z, Li Y, Wang J, Qin C and Zhang Y: PTBP knockdown overcomes the resistance to vincristine and oxaliplatin in drug-resistant colon cancer cells through regulation of glycolysis. Biomed Pharmacother 108: 194-200, 2018.

29. Wang X, Zhang M and Liu H: LncRNA17A regulates autophagy and apoptosis of SH-SY5Y cell line as an in vitro model for Alzheimer's disease. Biosci Biotechnol Biochem 83: 609-621, 2019.

30. Kilbas PO, Akcay IM, Doganay GD and Arisan ED: Bag-1 silencing enhanced chemotherapeutic drug-induced apoptosis in MCF-7 breast cancer cells affecting PI3K/Akt/mTOR and MAPK signaling pathways. Mol Biol Rep 46: 847-860, 2019.

31. Chen X, Dong XS, Gao HY, Jiang YF, Jin YL, Chang YY, Chen LY and Wang JH: Suppression of HSP27 increases the antitumor effects of quercetin in human leukemia U937 cells. Mol Med Rep 13: 689-696, 2016.

32. Tang H, Xiao WR, Liao YY, Li L, Xiao X, Xu XP and Feng H: EGFL7 silencing inactivates the Notch signaling pathway; enhancing cell apoptosis and suppressing cell proliferation in human cutaneous melanoma. Neoplasma 66: 187-196, 2019.

33. The American Association for Accreditation of Laboratory Animal Care. JAMA 207: 1707, 1969.

34. Cadona FC, Rosa JL, Schneider T, Cubillos-Rojas M, Sánchez-Tena S, Azzolin VF, Assmann CE, Machado AK, Ribeiro EE and da Cruz IBM: Guarana, a highly caffeinated food, presents in vitro antitumor activity in colorectal and breast cancer cell lines by inhibiting AKT/mTOR/S6K and MAPKs pathways. Nutr Cancer 69: 800-810, 2017.

35. Pandya KJ, Lefkopoulou M, Petrelli NJ, Vaughn DJ, Smith TJ, Harris JE and Haller DG; Eastern Cooperative Oncology Group: Phase II study of cisplatin and 5-fluorouracil (PF) and mitomycin C, vincristine, cisplatin and 5-fluorouracil (MVPF) in patients with metastatic large bowel cancer: An Eastern Cooperative Oncology Group study (EST 1285). Oncology 66: 118-125, 2004.

36. Sartore-Bianchi A, Loupakis F, Argiles G and Prager GW: Challenging chemoresistant metastatic colorectal cancer: Therapeutic strategies from the clinic and from the laboratory. Ann Oncol 27: 1456-1466, 2016.

37. Cheng J, Lv Z, Weng X, Ye S, Shen K, Li M, Qin Y, Hu C, Zhang $\mathrm{C}$, Wu J and Zheng S: Hsp27 acts as a master molecular chaperone and plays an essential role in hepatocellular carcinoma progression. Digestion 92: 192-202, 2015.

38. Zhang Y, Tao X, Jin G, Jin H, Wang N, Hu F, Luo Q, Shu H, Zhao F, Yao M, et al: A Targetable molecular chaperone Hsp27 confers aggressiveness in hepatocellular carcinoma. Theranostics 6: 558-570, 2016.

39. Fan YX, Abulimiti P, Zhang HL, Zhou YK and Zhu L: Mechanism of reversal of multidrug resistance by curcumin in human colorectal cancer cell line HCT-8/5-FU. Genet Mol Res: 16, 2017 doi: 10.4238/gmr16029414.

40. Jiang H, Ju H, Zhang L, Lu H and Jie K: microRNA-577 suppresses tumor growth and enhances chemosensitivity in colorectal cancer. J Biochem Mol Toxicol: 31, 2017 doi: 10.1002/jbt.21888.

41. Lee SL, Dempsey-Hibbert NC, Vimalachandran D, Wardle TD, Sutton PA and Williams JH: Re-examining HSPC1 inhibitors. Cell Stress Chaperones 22: 293-306, 2017.

42. Yang YX, Xiao ZQ, Chen ZC, Zhang GY, Yi H, Zhang PF, Li JL and $\mathrm{Zhu}$ G: Proteome analysis of multidrug resistance in vincristine-resistant human gastric cancer cell line SGC7901/VCR. Proteomics 6: 2009-2021, 2006.

43. Sun Y, Jiang Y, Huang J, Chen H, Liao Y and Yang Z: CISD2 enhances the chemosensitivity of gastric cancer through the enhancement of 5-FU-induced apoptosis and the inhibition of autophagy by AKT/mTOR pathway. Cancer Med 6: 2331-2346, 2017.

44. Demel HR, Feuerecker B, Piontek G, Seidl C, Blechert B, Pickhard A and Essler M: Effects of topoisomerase inhibitors that induce DNA damage response on glucose metabolism and $\mathrm{PI} 3 \mathrm{~K} / \mathrm{Akt} / \mathrm{mTOR}$ signaling in multiple myeloma cells. Am J Cancer Res 5: 1649-1664, 2015. 
45. Arques O,Chicote I,Puig I, Tenbaum SP, Argilés G,Dienstmann R, Fernández N, Caratù G, Matito J, Silberschmidt D, et al: Tankyrase inhibition blocks Wnt/ß-catenin pathway and reverts resistance to PI3K and AKT inhibitors in the treatment of colorectal cancer. Clin Cancer Res 22: 644-656, 2016.

46. Guerrero-Zotano A, Mayer IA and Arteaga CL: PI3K/AKT/mTOR Role in breast cancer progression, drug resistance, and treatment. Cancer Metastasis Rev 35: 515-524, 2016.

47. Liu B, Luo C, Zheng Z, Xia Z, Zhang Q, Ke C, Liu R and Zhao Y: Shengui Sansheng San extraction is an angiogenic switch via regulations of AKT/mTOR, ERK1/2 and Notch1 signal pathways after ischemic stroke. Phytomedicine 44: 20-31, 2018.
48. Shen F, Xiong Z, Kong J, Wang L, Cheng Y, Jin J and Huang Z: Triptolide impairs thioredoxin system by suppressing Notch1-mediated PTEN/Akt/Txnip signaling in hepatocytes. Toxicol Lett 300: 105-115, 2019.

49. Giachino C, Boulay JL, Ivanek R, Alvarado A, Tostado C, Lugert S, Tchorz J, Coban M, Mariani L, Bettler B, et al: A tumor suppressor function for notch signaling in forebrain tumor subtypes. Cancer Cell 28: 730-742, 2015. 